\title{
PA-038 COST-BENEFIT ANALYSIS OF MALARIA RAPID DIAGNOSTIC TEST IN ENUGU METROPOLIS, NIGERIA: THE PERSPECTIVE OF THE COMMUNITY PHARMACY PRACTITIONER
}

Ifeoma Ezennia, Obinna Ekwunife. Nnamdi Azikiwe University, Nigeria

\subsection{6/bmjgh-2016-000260.74}

Background Malaria is a great health burden in Nigeria. Since 2010, the World Health Organization issued guidelines that call for a shift from presumptive to test-based treatment. However, test-based treatment is still unpopular in community pharmacies in Nigeria. This could be due to unwillingness of customers to spend more for a rapid diagnostic test (RDT). It could also result from lack of interest from community pharmacy practitioners since they may perceive that there is no financial gain attached to the service. This study assessed the costs and benefits of test-based malaria treatment for the community pharmacy practitioner.

Methods The study was a community pharmacy-based cross sectional survey. Potential benefit of RDT test to the practitioner was determined using customers' willingness-to-pay (WTP) for this service. Average WTP was estimated using contingent valuation. Binary logistic regression was used to assess correlates of WTP. Costs associated with provision of RDT test were estimated. Costing was based on the provider's perspective. Probabilistic sensitivity analysis through Monte Carlo simulation was used to capture parameter uncertainty. The Benefit-cost ratio was calculated to determine study objective.

Results Average WTP was \$1.23 (95\% CI: \$1.03-\$1.44). Educated customers were 1.8 more likely to prefer RDT test before taking malaria treatment. Customers that understood RDT as described in the fact sheet were 18.3 times more likely to prefer RDT test before malaria treatment. The predictive capacity of the model was $18.1 \%$. Average cost [min - max] of the RDT test kit and the pharmacist's time spent for the test was $0.15[0.13-0.17]$ and 0.41 [0.18-0.52], respectively. The benefit-cost ration of test-based malaria treatment was 6.7 (95\% CI: 6.4-7.0).

Conclusions Test-based malaria treatment is cost-beneficial for pharmacy practitioners. Return on invested time was approximately 7 times. This finding should be capitalised upon to increase community pharmacy practitioners' interest and uptake of test-based malaria treatment. 